\title{
Simulating Land Cover Changes and Their Impacts on Land Surface Temperature in Onitsha, South East Nigeria
}

\author{
Ademola Akinbobola \\ Department of Meteorology and Climate Science, Federal University of Technology, Akure, Nigeria \\ Email: aakinbobola@futa.edu.ng
}

How to cite this paper: Akinbobola, A. (2019) Simulating Land Cover Changes and Their Impacts on Land Surface Temperature in Onitsha, South East Nigeria. Atmospheric and Climate Sciences, 9, 243-263. https://doi.org/10.4236/acs.2019.92017

Received: November 13, 2018

Accepted: April 21, 2019

Published: April 24, 2019

Copyright $\odot 2019$ by author(s) and Scientific Research Publishing Inc. This work is licensed under the Creative Commons Attribution International License (CC BY 4.0).

http://creativecommons.org/licenses/by/4.0/

\section{cc (i) Open Access}

\begin{abstract}
The increasing urbanization generally is brought about by many ecoenvironmental problems, such as the drastic change of land use and development of urban heat island. This study identified the pattern of land cover changes in Onitsha, South East Nigeria, and assessed the trend in temperature over the area from 1986 to 2016, simulated the land cover changes for 2030 and 2044, and estimated their impacts on land surface temperature (LST).
\end{abstract} These were with the view to determining the effects of changes in land use/cover on the LST in the area. Primary and secondary data were used for the study. The primary data were coordinates of geographic features within the study area, collected through the use of global positioning system. The secondary data were minimum and maximum temperature data from the Nigerian Meteorological Agency (NIMET), high-resolution Quick-bird imagery, Landsat TM/ETM imageries for four epochs (1986, 2002, and 2016) with path and row of 189 and 56. Individual components (bare surface, built-up, vegetation and surface water bodies) in the study area were extracted from the images. Radiometric correction was first performed (for 2016 landsat imagery) to fill the line scan corrector (LSC) gaps using Focal Analysis tool in ERDAS Imagine 14.0. This was followed with clipping of the satellite imagery to extract only those portions that are within the boundary of the study area. Supervised image classification was done for the three series of remotely sensed imageries to extract the spatial pattern of land cover change. The results revealed that the study area has been growing to a relatively compact urban agglomeration. The concentration of built-up area at the western and the central part of the study area has been getting larger and more aggregated. Built-up area increased by $11.49 \%$ from 1986 to 2002 and $5.68 \%$ from 2002 to 2016 while vegetation decreased by $6.03 \%$ from $50.26 \%$ in 1986 to $44.23 \%$ in 2002 . The decrease further continued from $44.23 \%$ in 2002 
to $29.79 \%$ in 2016 (change of $14.44 \%$ ). Expansion to spread into the sub-urban and rural communities bounding the metropolis, converting agricultural and green area to built-up areas. The land cover trend of the study area from the period of 1986-2016 shows dramatic changes for the dominant land cover types. The analyzed trend in temperature change shows that the central parts of the city have a temperature higher than the outlying parts. The results indicated that the average temperature of the study area increased from $24^{\circ} \mathrm{C}$ in 1986 to $28^{\circ} \mathrm{C}$ in 2016 . The simulated land cover also showed a decreasing trend in vegetal cover. The study concluded that the increase in built-up area caused an annual increase in land surface temperature $\left(0.31^{\circ} \mathrm{C}\right)$ over the study period.

\section{Keywords}

Land Surface Temperature, Land Use/Land Cover, Landsat, Onisha

\section{Introduction}

The land use/land cover pattern of a region is the product of natural and socio-economic factors [1]. Land use/land cover (LU/LC) is a dynamic and complex process that can be exacerbated by a number of human activities. Factors driving LU/LC change include an increase in human population and population response to economic response. Despite the social and economic benefit of LU/LC change, this conversion of LU/LC usually has an unintended consequence on the natural environment. For example, LU/LC change has been shown to negatively impact on stream water quality/quantity and stream ecosystem health [1] [2] [3]. Changing LULC has also been shown to influence weather patterns and the generation of streamflow [1] [4] [5].

The knowledge of land use/land cover change is important to understand some occurrences in the earth's biophysical composition. It entails a conversion of natural types of land to uses associated with the growth of population and economy, transforming the landscape from its natural form to impervious urban lands termed cities and towns. [6] Observed that, "cities are expressed as the nodes of man's greatest impact on nature, the places where he has most altered the essentially reserved resources such as land, air, water and even organisms. A city is the quintessence of man's capacity to induce and control changes in his habitat. Through urbanization, man has created new ecosystems within which the interactions of man, his works and nature are examples". Urbanization is therefore a necessary process that leads to the formation of what we now have as urban areas, which is not without its consequences, one of which is the modification of land surface and atmospheric boundary conditions that lead to a modified thermal climate which leaves the cities warmer than surrounding non urbanized areas.

Previous researches have shown that urban areas differ substantially in their 
micro-climate [7] [8] [9]. These differences are caused by the alteration of the earth's surface by human activities such as construction: which causes concrete, asphalt and glass to replace natural vegetation. The vertical surfaces of buildings added to the normally flat rural landscape and the release of artificially created energy into the environment from factories, industries and refineries also form a part.

Land surface temperature (LST) is the temperature of the skin surface of land which can be derived from satellite information or direct measurements. The LST provides an accurate measure for indicating energy exchange balance between the Earth and the atmosphere [10]. The LST shows a high spatial heterogeneity. The degree of LST is affected by land surface attributes, which are significantly influenced by elevation, slope and aspect which exert direct control on the incoming solar radiation [11]. Besides, topography is one of the factors that control the soil moisture distribution, thus exerting an additional influence on land surface temperature. Variation in LST also may be subject to seasonality, time of day, sea breeze, surface air temperature, humidity, wind speed, and land use [12] [13]. Estimation of LST is much more complicated due to the earth surface heterogeneity. Apart from the attenuation in the transmitted radiance caused by the atmosphere, the problem is also complicated by the highly variable land surface emissivity (LSE) while in the case of land surface, the emissivity dynamics has a wider range and can vary over short distances. Moreover, a proper LST validation is also difficult because the derived LST is representative for the whole pixel, while point temperature measurements can vary over short distances.

Hence, a field validation is possible only for homogeneous areas such as dense vegetation [14].

A direct consequence of increase in the LST is a phenomenon popularly referred to as Urban Heat Island (UHI) which brings about changes in local weather and climate [15]. The surface temperature has indirect but considerably significant influence on air temperatures, especially the canopy layer that is closest to the surface. The green areas covered by vegetation act as lungs of the city and help in regulating the temperature thus observing low temperature. On the other hand, replacement of soil, water and vegetation by impervious asphalt, concrete, metal in urban areas has environmental implications including reduction in evapo-transpiration, rapid run-off and increase in surface temperatures lea ding to creation of UHIs. It has been observed that majority of the world's population live in urban fringe causing an unprecedented expansion of urban areas. In Nigeria for example, the years 1980 to 2000 saw a 5\% growth rate in urban population while total population growth was $30 \%$ [16].

Onitsha metropolis and environs have been growing at a continuous rate of 2.83\% (National Population Commission) for decades resulting in rapid expansion and spread of settlements and towns in and outside the city. This makes the demand for standardized land use and land cover data to increase in seeking to assess and manage areas of critical concern for environmental control such as 
flood plains and wetlands, energy resource development and production areas, wildlife habitat, recreational lands, and areas such as major residential and industrial development sites. Therefore the study seeks to determine the effects of changes in land use/land cover on land surface temperature in Onisha, a commercial city, Southeast, Nigeria.

\section{Methodology}

\subsection{Study Area}

The study area, Onisha is popularly referred to as one of the rich commercial nerves in Nigeria. The town located on the fringes of the River Niger is basically a business centre with a population of well over one million people. Onitsha has grown to be one of the largest commercial cities hosting the biggest market in West Africa. Renowned as the "Taiwan of Africa", Onitsha is the gateway to the eastern States of Nigeria.

Located between latitude $6.14^{\circ} \mathrm{N}$ and longitude $6.80^{\circ} \mathrm{E}$ it has an average elevation of $106.32 \mathrm{~m}$ above mean sea level and occupies the eastern bank of River Niger, covering some 50 square kilometers. The influx of traders from all parts of the country and Cameroun invariably contributed to the town's physical and population growth. The low price of commodities in Onitsha market, the wide range of goods, and the accessibility and low cost of transportation to and from the town continue to draw people. Onitsha's location on the Niger River is advantageous; in addition, the bridge over the Niger makes the town the only gateway between south-eastern and south-western Nigeria.

Situated in the south equatorial climate region of Nigeria, Onitsha has an average annual rainfall of about 1850 millimetres. Mean annual temperature ranges from $23^{\circ} \mathrm{C}$ to $37^{\circ} \mathrm{C}$. Geologically, Onitsha and its neighbouring towns are situated within the vast sedimentary basin of the Niger-Benin trough of the upper middle Eocene strata known as the Bende Ameke group. Onitsha falls within the high forest belt of Niger. The vegetation of this region is light forest interspersed with tall grasses. The study area is drained mainly by the Niger River and its many tributaries, notably Anambra (which lends the state its name), Nkissi, and Idemili Rivers, all draining into the Niger (Figure 1).

\subsection{Data Type and Source}

In this study, both primary and secondary data sets were used. The primary data are basically those collected by the researcher while the secondary data are retrieved from archived resources.

\subsubsection{Primary Data}

The primary data collection involved is the latitude and longitude of selected features within the study area using the Garmin 78SC handheld Global Positioning System (GPS). The Garmin 78SC is accurate within 15 meters (49 feet) $95 \%$ of the time. This data basically assist in image processing and the implementation of 'Supervised' classification procedure on the images. 


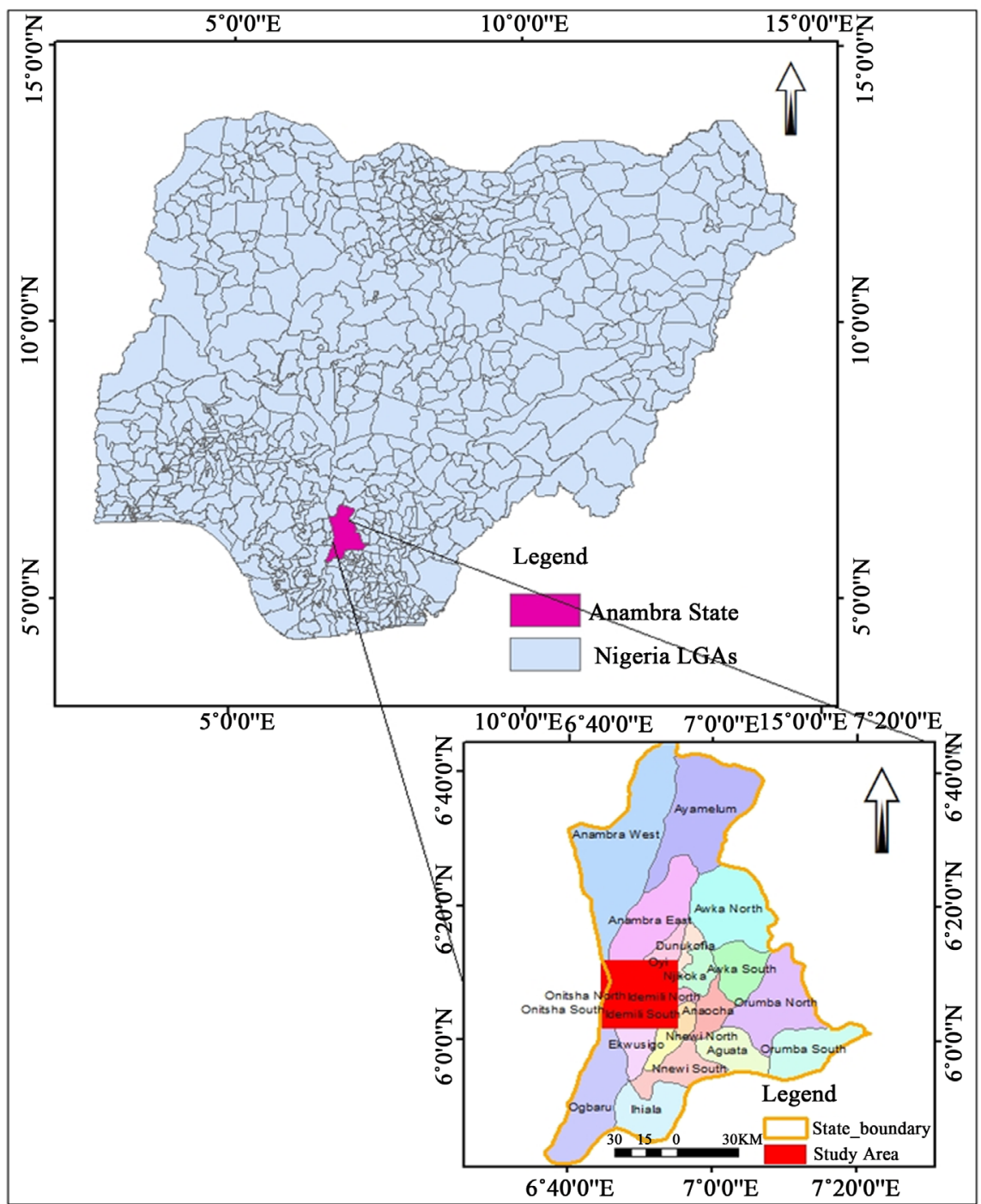

Figure 1. Map of onitsha in Anambra State.

\subsubsection{Secondary Data}

The secondary data comprises of both the climatic and remote sensing data. The climatic data include; monthly air temperature data for the period under study which is gotten from the Nigerian Meteorological Agency (NIMET), The Remote Sensing data on the other hand include; Landsat

TM/ETM+ imageries of the study area for $\left(21^{\text {st }}\right.$ December $1986,28^{\text {th }}$ January 2002 and $4^{\text {th }}$ February 2016) with path and row of 189 and 56. These serve as the fundamental dataset for which supervised classification was carried out with various categorization to ascertain the different changes in the land use over time and upon which future predictions land use change were based.

\subsubsection{Detailed Characteristics of the Data Sets}

The characteristics of both the climatic data and remote sensing images used in the study are summarized in Table 1 . The Landsat imageries $(30 \mathrm{~m})$ were downloaded from the official website of Global Land Cover Facility (GLCF) 
Table 1. Characteristics of datasets for the study.

\begin{tabular}{cccccccc}
\hline S/N & Data Type & Acquisition Date & Path/Row & Format & $\begin{array}{c}\text { Spectral } \\
\text { Resolution }\end{array}$ & $\begin{array}{c}\text { Spatial } \\
\text { Resolution (m) }\end{array}$ & Source \\
\hline 1 & Temperature & $1986-2016$ & Nil & Text & Nil & Nil & Nigerian Meteorological Agency \\
2 & Landsat TM & $21-$-Dec-86 & $189 / 56$ & Digital & 4 bands & 30 & Global Land Cover Facility \\
3 & Landsat ETM+ & 28-Jan-02 & $189 / 56$ & Digital & 7 bands & 30 & Global Land Cover Facility \\
4 & Landsat EMT+ & 4-Feb-16 & $189 / 56$ & Digital & 7 bands & 30 & Global Land Cover Facility \\
\hline
\end{tabular}

http://glcf.umiacs.umd.edu. This is hosted by the University of Maryland and access is free.

\subsection{Method of Analysis}

This study used data acquired from a remote sensing satellite that is hosted by the University of Maryland in the United State of America (Global Landcover Facility). The Landsat TM was acquired for $21^{\text {st }}$ December 1986, Landsat ETM+ for $28^{\text {th }}$ January 2002 and Landsat ETM+ for $4^{\text {th }}$ February 2016. The process of data analysis for this study is basically divided into three phases: Land use/cover change assessment, retrieval and estimation of Land Surface Temperature (LST) from Landsat data, and finally Simulation of Future Land Use change in the study area. In other to assess the level of possible transition of the study area in the future, spatial analysis of the land use land cover distribution were carried using the present as a base for predicting the future. Markov Chain analysis was performed for the multi-temporal land cover images of 1986-2002, and 2002-2016 including prediction for 2030 and 2044.

\subsubsection{Land Use/Land Cover Change Assessment}

In assessing the land use land cover change in the study area from 1986 to 2016, image classification was first done so as to map out the various land use of the entire study area. Three major categorizations were made which include; Built up, Vegetation, and Surface water bodies, Image functionality in ILWIS 3.3 were used to carry out the classification operations and maximum likelihood algorithm was used. It should be noted that the classification process was carried out for the year 1986, 2002 and 2016. Analysis of change was the next phase of the assessment which involves the calculation of percentage change in areas occupied by the various land use categories from 1986 to 2016 from which the trend was further analyzed.

\subsubsection{Digital Image Processing}

Digital image processing refers to the processing of digitalizing images by means of a digital computer. A digital image is composed of a finite number of elements, each of which has a particular location and value. These elements are referred to as picture elements, image elements, pels, and pixels. Pixel is the term most widely used to denote the elements of a digital image. 
Image acquisition is the first process in the series of the fundamental steps in digital image processing and it involves preprocessing, such as scaling. The next step is image enhancement which is among the simplest and most appealing areas of digital image processing. The idea behind enhancement techniques is to bring out details that are otherwise obscured, or simply to highlight certain features of interest in an image.

Image restoration is the next step and it also involves improving the appearance of an image. However, unlike enhancement, which is subjective, image restoration is objective in nature, in the sense that restoration techniques tend to be based on mathematical or probabilistic models of image degradation. Restoring an image basically deals with correcting the geometry base on some ground control point (latitude and longitude) which are used to "geo-referenced" the images to a common coordinate system. In this case, the Universal Transverse Mercator (UTM) projection, Clarke 1880 ellipsoid, Minna Nigeria datum zone 32 north was used to define coordinates in the GIS environment using the $1^{\text {st }}$ order polynomials.

After restoring the satellite images, colour compositing is then performed to boost visual interpretation. Using TM bands 5, 4, 3 for 1986, ETM+ bands 5, 4, 3 for 2002 and ETM+ bands 5, 4, 3 for 2016 three colour composites were executed and maps generated.

With the generated map, a comparison of four land cover features was carried out and separately classified visually within the computer. The distinguished classes include:

Built-up area: This comprises mostly of buildings, streets, highways, parking lots, sidewalks etc. they are sometimes referred to as impervious surfaces since they disallow water from infiltrating into the ground. According to increases in impervious surfaces, and accompanying phosphorous, sediment, and thermal loads, can have profound negative impacts on water resources. Hence Percent impervious surface area has emerged as a key factor to explain and generally predict the degree of impact severity on streams and watersheds. Motivated by the importance of impervious surfaces, many researchers from various disciplines have attempted to estimate the amount and distribution of urban impervious surfaces. In these studies, satellite imagery has been very helpful as it could successfully characterize different land-cover and land-use types.

Vegetation: In a general sense, vegetation is an assemblage of plant species and the ground cover they provide. Their classification is based on the dominance of species in a community.

Vegetation can be broadly classified as woodland, shrub or grassland.

Surface waterbody: These are open surface water bodies such as reservoirs, dams, rivers and streams.

Bare surfaces: When considering land cover in a very pure and strict sense it should be confined to describe vegetation and man-made features. Consequently, areas where the surface consists of bare rock or bare soil are describing land itself rather than land cover. For instance sandy surfaces like a beach. 


\subsubsection{Image Classification}

Land cover information is an important data set for characterizing and monitoring an environment like a watershed because it reveals correlation with imperviousness and changes in natural landscape. This information can be obtained from geospatial analysis of multispectral aerial imageries. For the purpose of this study, definitions of the clusters were carried out in an interactive manner which was performed during the training process. It involves selection of pixels and grouping them into predefined classes based on their spectral reflectance. Maximum likelihood algorithm classifier was also used as the default classification algorithm for the comparison of the individual pixels with the clusters.

For this study land cover was achieved using the "image processing" functionality tool in ILWIS Academy, the "supervised" classification process was carried out.

Please note that before image classification was carried out, "Focal Analysis" had to be performed on images acquired above 2003 so as to fill the gaps occasioned by the failure in on-board line scan corrector. This was done in ERDAS IMAGINE 2014.

\subsubsection{Retrieval of Land Surface Temperature}

Surface radiant temperature is derived from geometrically corrected TM and ETM+ thermal infrared (TIR) channel (band 6). Band 6 records the radiation with spectral range in $10.4-12.5 \mu \mathrm{m}$ from the surface of the earth. The geometrically rectified images are free from distortions related to the sensor and Earth. Although the impact of the diurnal heating cycle on the LSTs will be an interesting issue to address, there has been no attempt to include it here because TM/ETM+ images do not provide day and night infrared images at the same day. This is why the variability of LST at overpass time in different years is not analyzed. Moreover, because absolute temperatures are not used for the purpose of computation, atmospheric correction was not carried out at this stage. It means no radiometric normalization has been performed. The LST was measured from the individual thermal images and were compared between different time periods. Based on the literature, different retrieval methods of brightness temperature from the TM and ETM+ images were applied as discussed below.

\subsubsection{Retrieval of LST from the Landsat 5 TM Images}

Based on [17], a two-step process was followed to derive brightness temperature from the Landsat 5 TM Images in this research. In the first step, the digital numbers (DNs) of band 6 were converted to radiation luminance $\left(R_{T M 6}\right)$ using the following formula:

$$
R_{T M 6}=\frac{V}{225}\left(R_{\max }-R_{\min }\right)+R_{\min }
$$

where, $V$ represents the DN of band 6, and

$$
\begin{aligned}
R_{\max } & =1.896\left(\mathrm{~mW} \cdot \mathrm{Cm}^{-2} \cdot \mathrm{Sr}^{-1}\right) \\
R_{\min } & =0.1534\left(\mathrm{~mW} \cdot \mathrm{Cm}^{-2} \cdot \mathrm{Sr}^{-1}\right)
\end{aligned}
$$


In the second step, the radiation luminance was converted to at-satellite brightness temperature in Kelvin, $T(\mathrm{~K})$, using the following equation:

$$
T=\frac{K_{1}}{\ln \left(K_{2} /\left(R_{T M 6} / b\right)+1\right)}
$$

where, $K_{1}=1260.56 \mathrm{~K}$ and $K_{2}=607.66\left(\mathrm{~mW} \cdot \mathrm{Cm}^{-2} \cdot \mathrm{Sr}^{-1}\right)$, which are pre-launch calibration constants under an assumption of unity emissivity; $b$ represents effective spectral range, when the sensor's response is much more than $50 \%, b=$ $1.239(\mu \mathrm{m})$.

\subsubsection{Retrieval of LST from the Landsat 7 ETM+ Images}

The retrieval of brightness temperature from the Landsat 7 ETM+ images was based on two steps. In the first step, the DNs of band 6 were converted to radiance based on the following formula:

$$
\text { Radiance }=\frac{\text { LMAX }- \text { LMIN }}{\text { QCALMAX }- \text { QCALMIN }} \times(\text { QCAL }- \text { QCALMIN })+\text { LMIN }
$$

where, information can be obtained from the header file of the images, QCALMIN $=1$, QCALMAX $=255$, QCAL $=$ DN, and LMAX and LMIN (also given in the header file of the images) are the spectral radiances for band 6 at digital numbers 1 and 255 (i.e. QCALMIN and QCALMAX), respectively.

In the second step the effective at-satellite temperature of the viewed Earthatmosphere system, under the assumption of a uniform emissivity, could be obtained by the following equation:

$$
T=\frac{K_{2}}{\ln \left(K_{1} / L_{\lambda}+1\right)}
$$

where, $T$ is the effective at-satellite brightness temperature in Kelvin; $K_{1}=666.09$ (watts/(meter ${ }^{2} \cdot$ ster $\left.\cdot \mu \mathrm{m}\right)$ ) and $K_{2}=1282.71$ (Kelvin) are calibration constants; and $L_{\lambda}$ is the spectral radiance in watts/(meter ${ }^{2} \cdot$ ster $\left.\mu \mathrm{m}\right) .(18)$

The temperature values derived in "Kelvin (K)" from the above two processes were converted into "Degree Celsius (C)" using the following equation:

$$
\mathrm{C}=\mathrm{K}-273.15
$$

Derivation of Normalized Difference Vegetation Index (NDVI): Using the image functionality tool in Idrisi Taigi, Normalised Difference Vegetation Index (NDVI) was calculated for the 1986, 2002 and 2016 satellite images of the study area to determine changes in vegetation health. NDVI was calculated using Red (R) and Near Infra-Red (NIR) bands of the three images using the formula:

$$
\mathrm{NDVI}=(\mathrm{NIR}-\mathrm{R}) /(\mathrm{NIR}+\mathrm{R})
$$

The NDVI values obtained where then used for the calculation of the surface emissivity which is a fundamental element in the retrieval of land surface temperature. The formula below was used to calculate land surface emissivity (LSE).

$$
P v=(\text { NDVI }- \text { NDVImin/NDVImax }- \text { NDVImin })^{2}
$$

$P_{V}=$ proportion of vegetation 


$$
e=0.004 P v+0.986
$$

Derivation of Normalized Difference Built up Index (NDBI): Using the image functionality tool in Erdas Imagine 2014, Normalized built up index was calculated using the following formular:

$$
(\mathrm{R} 1650-\mathrm{R} 830) /(\mathrm{R} 1650+\mathrm{R} 830)
$$

where R830 is equivalent to band 4 and R1650 is equivalent to band 5 of the Landsat images.

\subsubsection{Simulation of Feature Land Use/Land Cover Change for 2030 and 2044}

For the purpose of this research, Markov Chain technique was applied to project the future land cover patterns. The adoption of this technique is based on data availability, accuracy in outcomes and wide acceptability. The future states of the study area were modelled based on the immediate preceding state; in other words, the future states were predicted not on the basis of the past but rather the present. Initially the NDVI images were reclassified into suitable classes for Markov chain analysis. It produces a transition matrix, a transition areas matrix and a set of conditional probability images by analyzing two qualitative NDVI images from two different dates (2002 and 2016). Each conditional probability image shows the possibility of transitioning to another class. The next step was to make one single NDVI map for future prediction aggregating all the Markovian conditional probability images. The final predicted land cover map of 2030 will be based on the past fourteen year's land cover change pattern on the basis of Markov chain analysis. This prediction is performed by a Stochastic Choice decision model. Stochastic Choice creates a stochastic NDVI map by evaluating and aggregating the conditional probabilities in which each class can exist at each pixel location against a rectilinear random distribution of probabilities.

\section{Results and Discussion}

\subsection{Spatial Pattern of Land Cover Change Assessment}

The results of the changes in land cover in the study area are presented in Figure 2(a) and Figure 2(c) and Figure 2(e) with regards to the spatial coverage of land cover distributions and proportions for 1986, 2002, and 2016 respectively. Also the percentage of land cover categories are seen in Figure 2(b) and Figure 2(d) and Figure 2(f) respectively.

They show the result of the land cover map generated based on three major classes of land use/land cover categorization (Built-up Area, Vegetation and Waterbody).

The land use classification for 1986 derived from the Landsat TM satellite image (Figure 2(a) and Figure 2(b)) showed that majority of the study area was under Vegetation Area with $75.24 \%$. These are concentrated to the east, south and northern portions of the study area. The next land use is Built up which has an area coverage of $22.31 \%$ and is fully concentrated in the western and central 


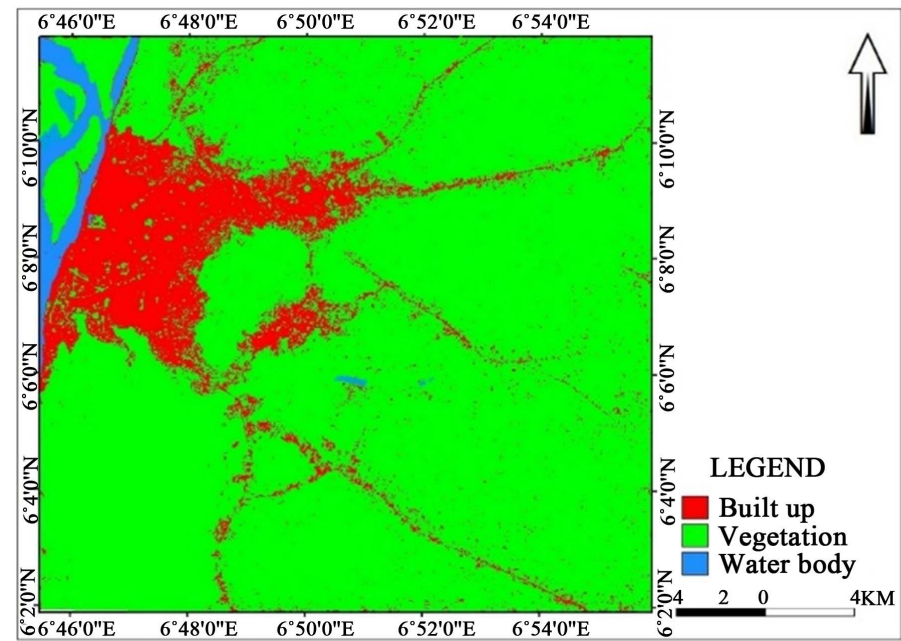

(a)

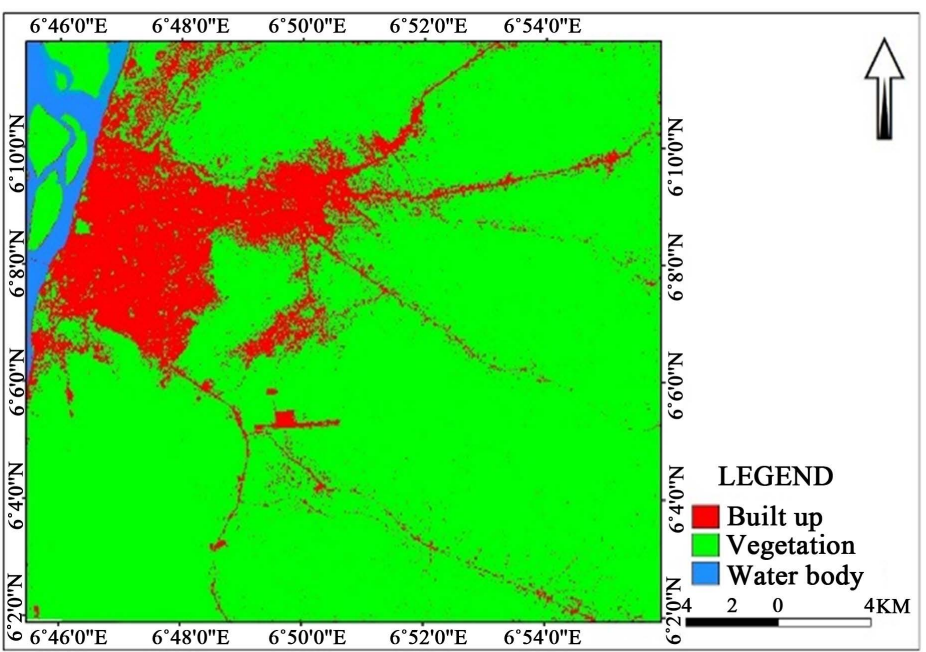

(c)

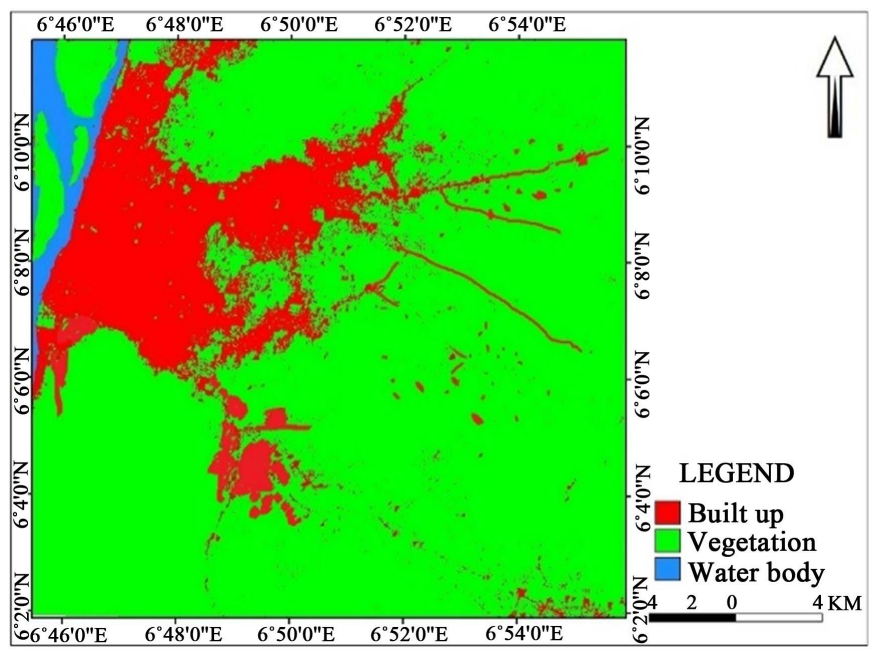

(e)

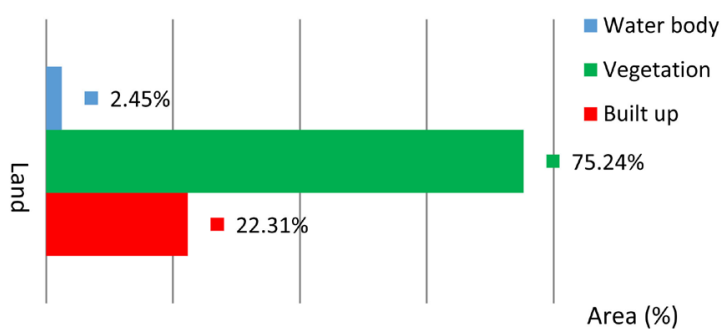

(b)
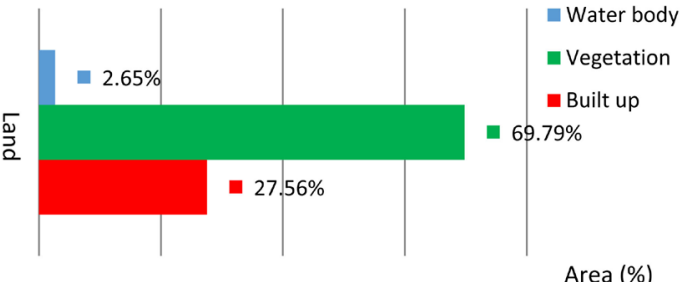

(d)

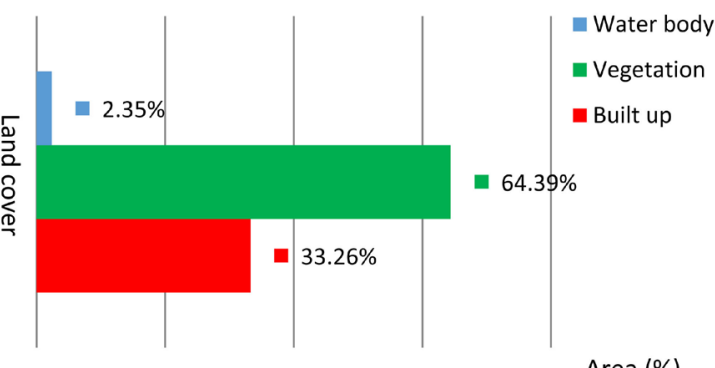

(f)

Figure 2. (a) Land cover map of Onitsha in 1986; (b) Areas in Percentage of Land Cover Categories 1986; (c) Land cover map of Onitsha in 2002; (d) Areas in Percentage of Land Cover Categories 2002; (e) Land cover map of Onitsha in 2016; (f) Areas in Percentage of Land Cover Categories 2016. 
parts with patches towards the north-eastern and southern region of the study area. Waterbody is next in area and it occupies about $2.45 \%$ and it has an area coverage located mainly to the north-west, running through and finding its way to the western part of the study area.

The spatial extent of the 2002 land cover shows that vegetation areas have experienced a drop in coverage by $5.45 \%$. Although it still occupied the largest area coverage with (69.797\%) as compared to other land cover classes. This is largely concentrated around the eastern, south-eastern and northern part of the study area (Figure 2(c)). Built-up Area is seen to have gained more coverage rising from $22.31 \%$ in 1986 to $27.56 \%$ in 2002 (Figure 2(d)). It is mainly concentrated along the western and central part extending towards the eastern portion of the entire study area. Waterbody on the other hand is seen to have gained just a little above the previous year increasing from $2.45 \%$ to $2.65 \%$ (an increase of $0.2 \%$ ). The region of concentration is still within the river Niger channel in the north-western portion. This period witnessed migration and urban expansion in terms of physical changes leading to the construction of more roads, residential, commercial and institutional facilities as well as essential services. Settlements were gradually expanding and becoming more clustered partly due to migration and population increase. The beginning of such change in land use was strongly attributed to human activities.

Finally, in 2016 land use distribution yielded a classification with Vegetation Area still experiencing continuous decrease even though it remains the class with the highest coverage. The result shows that in this period, the vegetal cover has dropped to almost half of the original value when compared to the earliest epoch, with value coming down to as low as $64.39 \%$ of the entire study area (Figure 2(f)). Also, it is seen to be covering mainly the south-western, south-eastern and the northern axis (Figure 2(e)). Built-up Area experienced a drastic increase compared to the other epochs covering an area of $33.26 \%$ (Figure $2(f)$ ) and is mainly concentrated at the western and central part with its density fully experienced at the southern and north-eastern part with patches also spread all around the entire study area., Waterbody having (2.35\%) is mainly gradually experiencing decrease with concentration within the reservoir in the north-western and western portion. This period possibly witnessed unprecedented and continuous increase in population, proliferation of industries, and increase in physical developments majorly from the government and private developers and encroachment arising from series of anthropogenic activities caused by the drive to satisfy the housing demand arising from population increase and their need of industrialization. The implication of this transformation is the continuous damage to vegetal covers and the resultant increase in local temperature which by extension leads to rise in the regional temperature.

\subsection{Normalized Difference Vegetation Index}

The spatial distribution of NDVI values from the Landsat TM image of 1986 can be seen in Figure 3(a). The NDVI values are in the range of -0.26 to 0.43 , having 


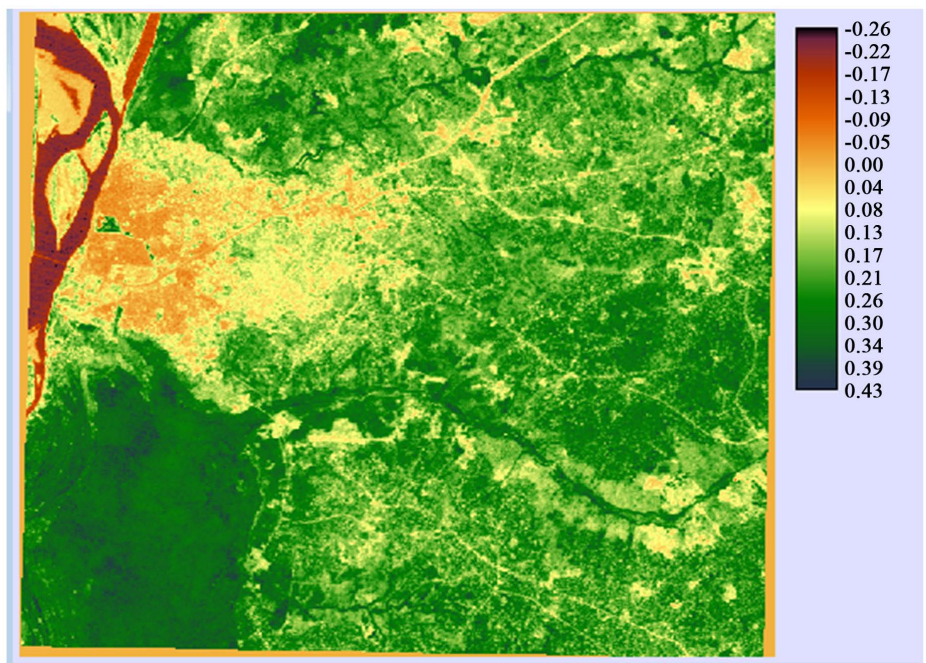

(a)

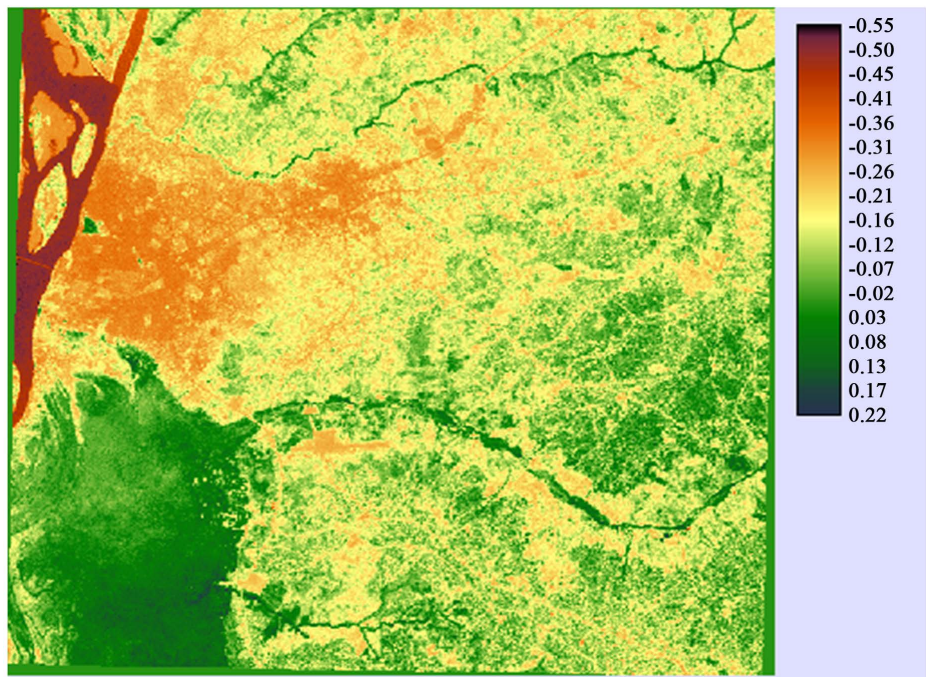

(b)

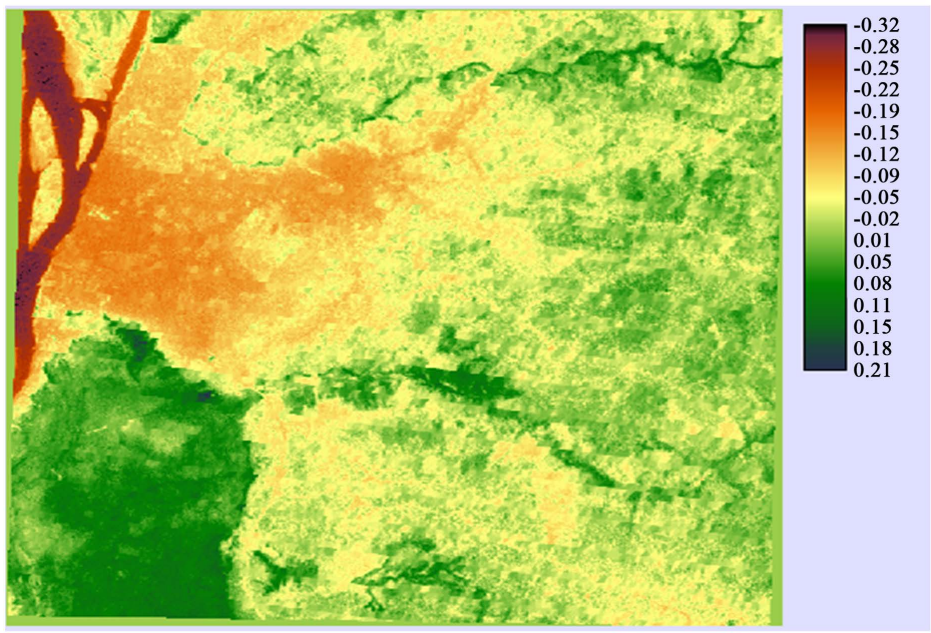

(c)

Figure 3. (a) Spatial Distribution of NDVI for Onitsha in 1986; (b) Spatial Distribution of NDVI for Onitsha in 2002; (c) Spatial Distribution of NDVI for Onitsha in 2016. 
a mean value of 0.186 and a standard deviation of 0.11 . This figure shows that High values of NDVI (dark green) that were observed in the southwestern, eastern and around the northern parts of the image correspond to parks and green spaces. Low values of NDVI correspond to areas of heavy commercial, industrial and residential activity. This also includes wasteland and bare soil areas. As presented from the image, the hub of these activities is concentrated in the West and central part of the study area with patches around the north-eastern and south-eastern region. The medium NDVI values were observed over fallow land and asphalt roads, in the central, north-eastern and south-eastern parts of the study area.

Figure 3(b) shows the result of the spatial distribution of NDVI obtained from the Landsat ETM+ image of 2002. The NDVI values are in the range of -0.55 to 0.22 , having a mean value of -0.132 and a standard deviation of 0.116 . The result clearly indicates that areas with Low values of NDVI have experienced unprecedented expansion when compared to the previous year. This is not unconnected to the continuous rise in commercial, industrial and residential activity. As seen from the image, water bodies, wasteland and bare soil also form this region of low NDVI. These are fully concentrated in the west and central part of the study area, spreading continuously to the north, east and western region. In the figure it shows that High values of NDVI (dark green) that were observed in the southwestern, eastern and little patches around the southern and northern parts of the image correspond to reserved and green spaces while the medium NDVI values were observed over fallow land and asphalt roads, in the central, north-eastern and south-eastern parts of the study area.

Figure 3(c) also shows the result of the spatial distribution of NDVI obtained from the Landsat ETM+ image of 2016. The NDVI values are in the range of -0.32 to 0.21 , having a mean value of -0.031 and a standard deviation of 0.072 . The result clearly indicates that areas with Low values of NDVI are non-vegetated areas with water body showing the lowest values followed by areas of commercial, industrial and residential activities. Although the region of low NDVI values is getting thicker and expanding, the results show that the NDVI values have reduced when compared to the previous epoch. This phenomenon is not unconnected to the review of government policies on environmental protection and recovery with strong emphasis on impact assessment. The region of low NDVI is found to be concentrated in the west, central and southern part of the study area, spreading continuously to the north and east region. In the figure it shows that High values of NDVI (dark green) are observed in the southwestern, eastern and north-eastern parts of the image while the medium NDVI values were observed over fallow land and asphalt roads, in the central, north-eastern and south-eastern parts of the study area.

\subsection{Changes in Land Surface Temperature}

The spatial distribution of surface temperature of the 1986, 2002 and $2016 \mathrm{im}$ ages is shown in Figures 4(a)-(c). Surface temperature of the 1986 LST image 


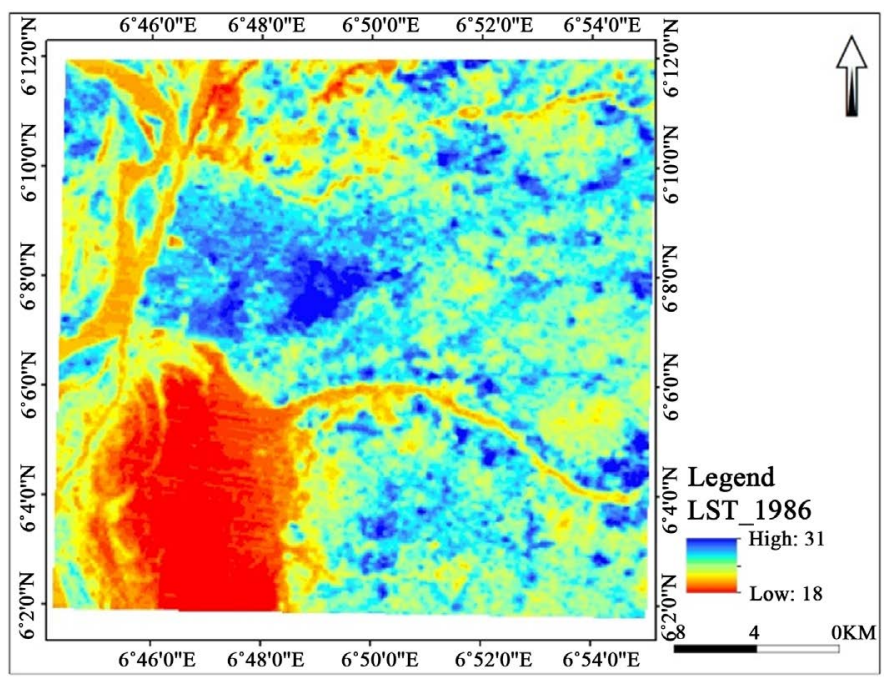

(a)

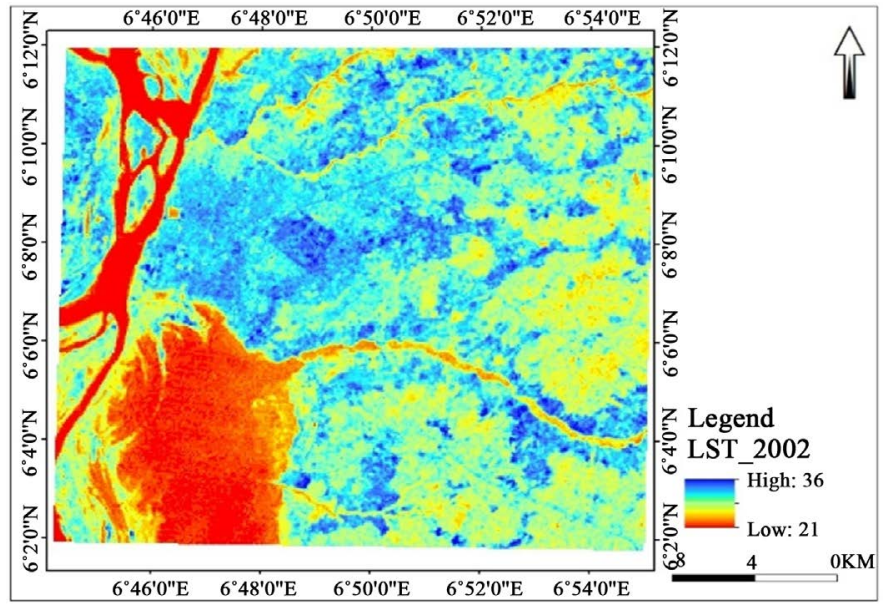

(b)

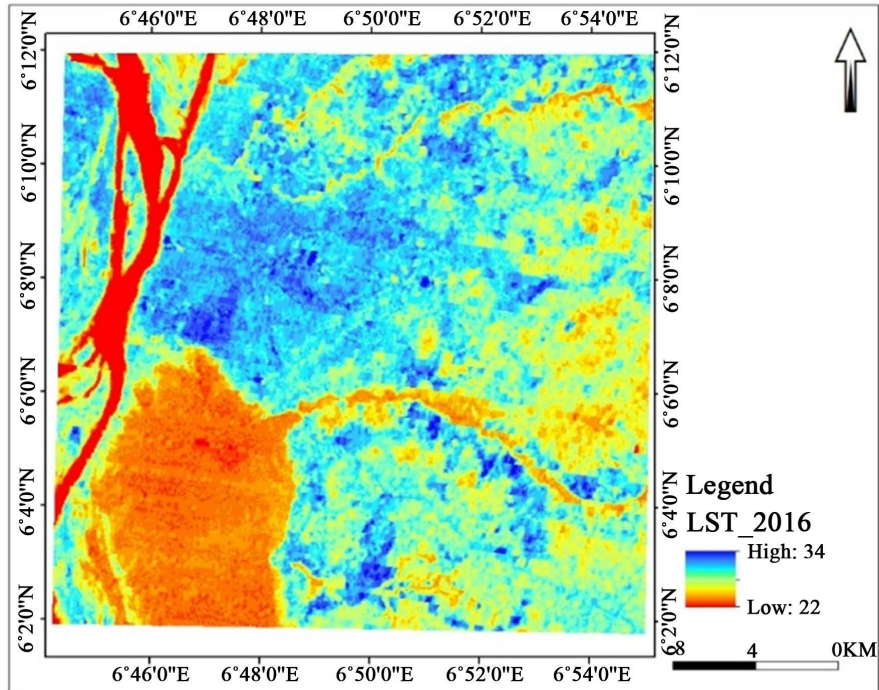

(c)

Figure 4. (a) Spatial Distribution of LST for Onitsha in 1986; (b) Spatial Distribution of LST for Onitsha in 2002; (c) Spatial Distribution of LST for Onitsha in 2016. 
ranged from $18^{\circ} \mathrm{C}$ to $31^{\circ} \mathrm{C}$ (mean of $24^{\circ} \mathrm{C}$ ), surface temperature of the $2002 \mathrm{LST}$ image ranged from $21^{\circ} \mathrm{C}$ to $36^{\circ} \mathrm{C}$ (mean of $29^{\circ} \mathrm{C}$ ) while the surface temperature of the $2016 \mathrm{LST}$ image ranged from $22^{\circ} \mathrm{C}$ to $34^{\circ} \mathrm{C}$ with a mean value of $28^{\circ} \mathrm{C}$. In the figures high surface temperatures are shown by the dark blue areas, this means that central parts of the city have a temperature higher than the outlying parts. The results indicated that the average temperature of Onitsha increased from $24^{\circ} \mathrm{C}$ in 1986 to $29^{\circ} \mathrm{C}$ in 2002 . This can be traced to developments in asphalt roads, residential and commercial areas which increased dramatically between 1986 and 2002, and reduction in vegetation cover. The combination of the mentioned factors brought about the increase in the overall temperature of the city.

However, the period from 2002 to 2016 experienced slight drop in average land surface temperature from $29^{\circ} \mathrm{C}$ in 2002 to $28^{\circ} \mathrm{C}$ in 2016 respectively. This is due to the fact that residential areas had a slight decrease in their surface temperatures as a result of modernization with many residential and commercial buildings having cooling devices, which are installed in them. None the less, it is generally observed that surface temperature in Onitsha has been increased in all types of land use/cover, but the greatest increase is registered in the commercial and industrial sites.

In terms of the percentage area coverage, Figure 4(a) shows that no area in Onitsha experienced a temperature of $>31^{\circ} \mathrm{C}$ in $1986.8 .59 \%$ of the total area coverage was under $18^{\circ} \mathrm{C}-20^{\circ} \mathrm{C}, 45.12 \%$ under $20^{\circ} \mathrm{C}-24^{\circ} \mathrm{C}, 42.56 \%$ under $24^{\circ} \mathrm{C}$ - $27^{\circ} \mathrm{C}$ and $3.73 \%$ under $27^{\circ} \mathrm{C}-31^{\circ} \mathrm{C}$ respectively. On the other hand, Figure 4(b) shows that around $72.3 \%$ areas of Onitsha experienced this temperature level in 2002, which was found to increase to around 98.46\% in 2016. Another noticeable fact is that in 2002 and 2016 no area remained under $18^{\circ} \mathrm{C}-20^{\circ} \mathrm{C}$ instead there was drastic increase of the temperature zones to as high as $31^{\circ} \mathrm{C}$ to $37^{\circ} \mathrm{C}$ which is seen to occupy $27.7 \%$ of the entire study area in 2002 and $1.53 \%$ in 2016 (Figure 4(c)) respectively.

A close observation of the temperature trend is seen to be such that in 1986 a larger part of the Onitsha area (53.71\%) fell within the lower temperature zones $\left(<18^{\circ} \mathrm{C}\right.$ to $\leq 24^{\circ} \mathrm{C}$ ) (Table 2). But in $2002,59.44 \%$ was found to be within the

Table 2. Area of Land Surface Temperature (LST) classes from 1986 to 2016.

\begin{tabular}{lccc}
\hline & 1986 & 2002 & 2016 \\
\cline { 2 - 4 } 18 to $\leq 20$ & 8.59 & Coverage (\%) & 0 \\
20 to $\leq 24$ & 45.12 & 0 & 3.76 \\
24 to $\leq 27$ & 42.56 & 12.86 & 25.77 \\
27 to $\leq 31$ & 3.73 & 9.21 & 68.93 \\
31 to $\leq 34$ & 0 & 50.23 & 1.53 \\
34 to $\leq 37$ & 0 & 26.37 & 0 \\
\hline
\end{tabular}


mid-temperature zone ( $\geq 24$ to $\leq 31$ ) while $27.7 \%$ were within the higher temperature zones ( $\geq 31$ to $\leq 37$ ) (Figure 4.13) [18]. It also shows a variation in the trend as larger portion of the Onitsha area (94.7\%) moved into the mid-temperature zones ( $\geq 24$ to $\leq 31$ ) in 2016 and leaving just $1.53 \%$ under the higher temperature zone and $3.76 \%$ within lower temperature zone.

This finding is in agreement with the research of [19] which found out that no area in DMP experienced a temperature of $\geq 30^{\circ} \mathrm{C}$ in 1989 . Around $0.35 \%$ areas of the DMP experienced this temperature level in 1999, which was found to increase to about $5 \%$ in 2009 . In 1989, a larger part of the DMP area (74\%) fell within the lower temperature zones $\left(<18^{\circ} \mathrm{C}\right.$ to $\left.<21^{\circ} \mathrm{C}\right)$ while in 1999 , a majority of the area $(91.40 \%)$ was found to fall into the mid-temperature zones $\left(21^{\circ} \mathrm{C}\right.$ to $<27^{\circ} \mathrm{C}$ ). Their result shows that the trend continues, and a larger portion of the DMP area $(44 \%)$ moved into the higher temperature zones $\left(27^{\circ} \mathrm{C}\right.$ to $\left.<30^{\circ} \mathrm{C}\right)$ in 2009.

\subsection{Estimation of Land Use/Land Cover Change Future Scenario}

Results of the MLP Markov Chain Models were focused predominantly on providing the knowledge of how much, where, what type of land use/land cover change would occur from 2016 to 2030 and from 2030 to 2044.

As observed from the result, it is evident that built up area continuously increase and this trend is not different from the previous scenario for 2002 and 2016. It is expected to be on the rise unless it is checked. The projected land cover scenario also indicate similar spatial distribution and trend with an expectation of continual decrease of vegetation cover and increase in bare surface while water bodies remain almost constant (Figure 5(a) and Figure 5(b)). More expansion is expected from 2030 to 2044 (Figure 5(c) and Figure 5(d)).

This result also clearly shows the disappearance of vegetal cover on a continuous scale and it is expected that both the sub-urban and rural areas where vegetation is predominant in the previous years would still experience serious change that will leave them with little or no vegetation in the nearest future. The direct consequence is the expansion of built-up towards these areas by 2030 and 2044. However it should be mentioned that this change is a function of the sustenance of the driving forces/mechanism of continual growth.

A quantitative assessment of the simulated land cover scenario Figure 5(a) and Figure 5(c) suggested that approximately $11.59 \%$ of areas covered by mostly vegetation in 2016 will be modified to built-up and bare surface area by 2030 . Similarly, about $8.99 \%$ of the areas covered by both vegetation and bare surface categories in 2030 is expected to be converted to built-up by 2044 . In all, there will be sustained rise in built-up area to $32.69 \%$ and $41.68 \%$ by 2030 and 2044 respectively (Figure 5(a) and Figure 5(b)). This will be manifested in the corresponding decrease in the areas covered by vegetation and bare surface while changes in water bodies remain almost insignificant. The prediction of the future scenario in land use change in the study area suggested a continued degradation of the forest, light and thick vegetation resulting in more degraded lands. 


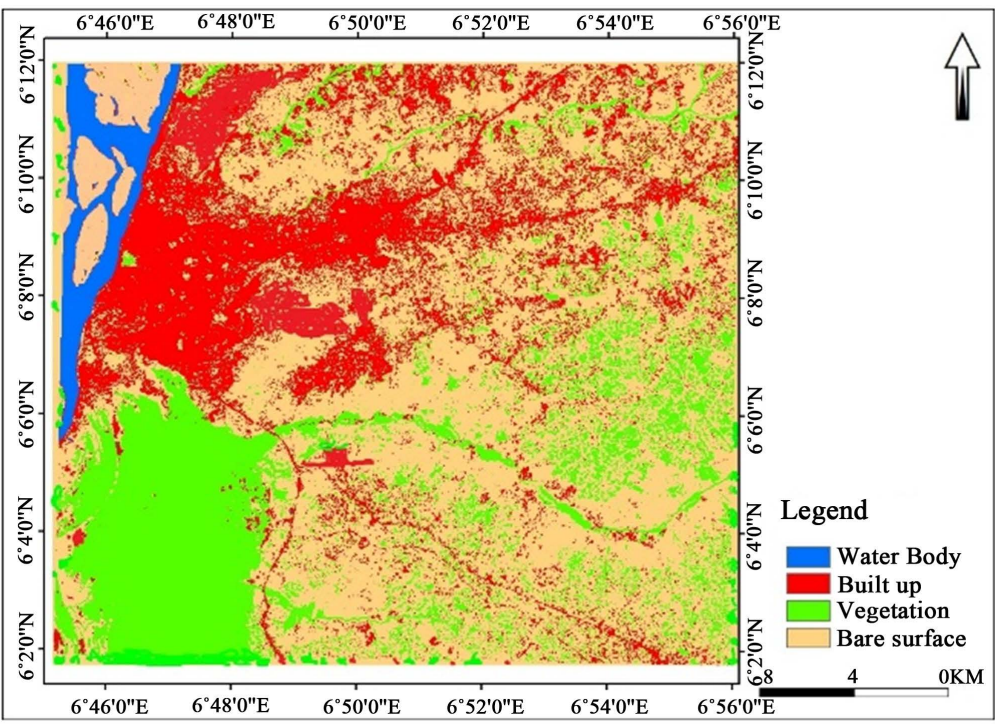

(a)

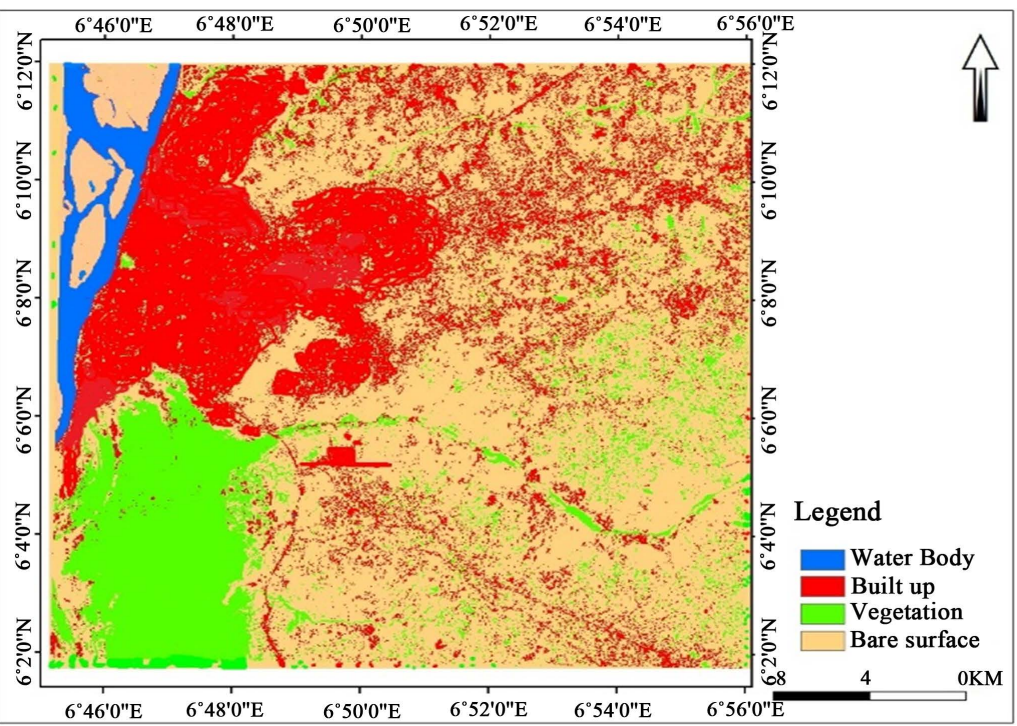

(c)

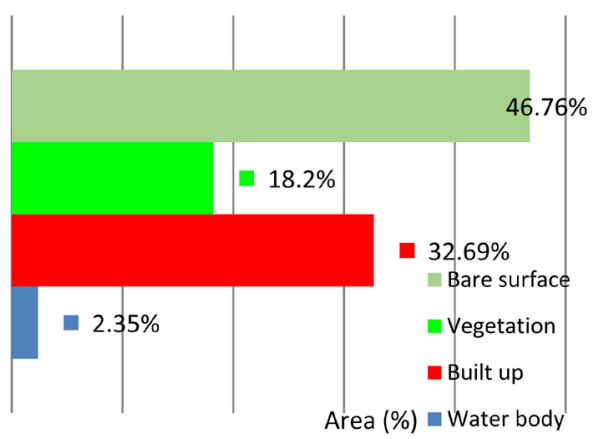

(b)

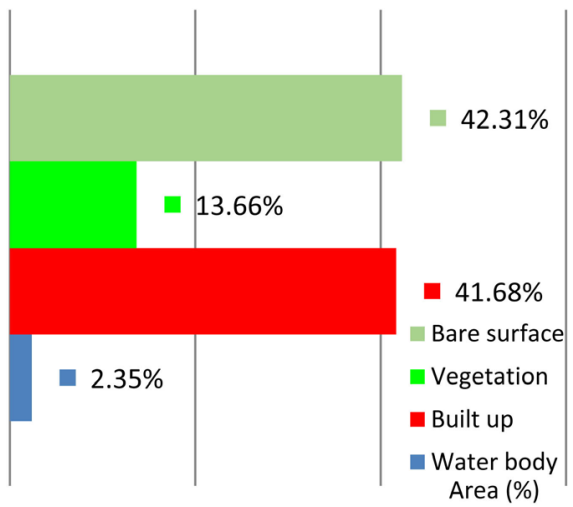

(d)

Figure 5. (a) Projected Land Cover Map of Onitsha for 2030; (b) Simulated percentage of area covered by land cover in Onitsha for 2030; (c) Projected Land Cover Map of Onitsha for 2044; (d) Simulated percentage of area covered by land cover in Onitsha for 2044

It should be noted that the degradation of vegetation could increase surface thermal response, reduced precipitation, increase surface runoff and promote soil erosion.

This study is borne out of the urgent need to look into the impacts of industrialization and commercialization which are product of urbanization in the study area in terms of its effect on the original state of natural resources and modification of land surface temperature. The study utilizes relevant maps with high and medium resolution satellite imagery and series of other Remote Sensing techniques to identify the pattern of land cover changes for the period under study, analyse the trend in temperature change from 1986 to 2016, simulate land 
cover changes for 2030 and 2044, and estimate their impacts on land surface temperature (LST) in respective periods. These are all in line with the aim of this research.

To address the first objective, Land Cover map for 1986, 2002 and 2016 for the study area were derived utilizing standardized digital remote sensing classification techniques in Idrisi Taiga. The classification employed TM bands 5, 4, 3 for 1986, ETM+ bands 5, 4, 3 for 2002 and ETM+ bands 5, 4, 3 for 2016. The classification comprised of four land use/land cover features classes (Built-up area, vegetation Area, Bare Surface, and Waterbody) with the use of maximum likelihood algorithm. Final classification accuracy was determined for all the epochs to be satisfactory or "good" by means of employing standardized accuracy assessment measures and error matrix. The process of change detection was employed by utilizing image differencing method. This process entailed subtraction of the difference in the mean values between Landsat image of 1986 from the Landsat images of 2002 and 2016, followed by subsequent change delineation.

To analyse the trend in temperature change over the period, the Land Surface Temperature for 1986, 2002 and 2016 were retrieved from the various landsat imageries for each year. This was carried out through the retrieval of brightness temperature by converting DNs of band 6 to radiance then the effective at-satellite temperature of the viewed Earth-atmosphere system, under the assumption of a uniform emissivity was calculated using relevant equations. Maps were then generated for each epoch to examine the trend in temperature change.

To simulate land cover changes for 2030 and 2044, Markov Chain technique was applied. The future state of the study area for 2030 and 2044 is modelled based on the immediate preceding state which produced a transition areas matrix and a set of conditional probability. Each conditional probability image shows the possibility of transitioning to another class. The final predicted land cover map of 2030 was based on the past fourteen year's land cover change pattern on the basis of Markov chain analysis from 2016 to 2030 and 2030 to 2044 . Maps were then generated to visually represent the change scenario.

The findings of the study indicate that the study area (Onitsha) has been growing to a relatively compact urban agglomeration. The concentration of built-up area at the western and the central part of the study area has been getting bigger and more aggregated. The expansion is not also limited to the urban fringes alone but is spreading heavily to the sub-urban and rural communities bounding the metropolis, converting agricultural and green area to built-up areas. The built-up areas have mainly occurred in the western, central, north-eastern and south-eastern part of the study area with a lot of establishment of industrial and commercial centers leading to development of new residential and infrastructural facilities.

The land cover trend of the study area from the period of 1986-2016 shows dramatic changes for the dominant land cover types, which are bare surface, built-up and vegetation. Built-up area has increased by $17.17 \%$ (from $9.67 \%$ in 1986 to $26.84 \%$ in 2016). 
The area experienced an unprecedented growth in the last few years with built-up area increasing by $11.49 \%$ from 1986 to 2002 and $5.68 \%$ from 2002 to 2016. On the contrary, vegetation has decreased by $6.03 \%$ from $50.26 \%$ in 1986 to $44.23 \%$ in 2002 . The decrease further continued from $44.23 \%$ in 2002 to $29.79 \%$ in 2016 (change of 14.44\%). Direct consequences of this were the disappearance of the green and vegetal cover leading to exposure of the area to solar energy. The land cover changes have impacted on the land surface temperature in the study area. The increasing trend of built-up and decreasing trend of vegetated area over the years has led to the overall increase in Land Surface Temperature within the area under study.

It is evident in the research that the study area is experiencing significant temperature changes as a result of the series of activities particularly industrial and commercial activities leading to construction of mass housing and industrial estates within it. This is impacting seriously on its physical environment and causing serious devastation of the vegetal cover and natural resources. Of course the commercialization/industrialization is not the only cause of change but is evidently the most important. Other anthropic activities include farming, grazing and bush burning. Also in recent times, the study area is experiencing heavy influx of people thus leading to increase in human population which has further increased growth in infrastructural development and expansion of housing estate, which consequently have negative influence on the natural environment.

\section{Conclusion}

This research has shown that the amount of built-up area has doubled between 1986 and 2002, and is seen to increase from 2002 to 2016. This increase is expected from 2016 to 2030 and beyond. More areas in Onitsha are gradually shifting from the mid-temperature zones toward the highest temperature zone due to the expansion of built-up areas, and if the current trend continues then almost the entire study area will be an UHI in 2044 .

\section{Conflicts of Interest}

The author declares no conflicts of interest regarding the publication of this paper.

\section{References}

[1] Weng, Q. (2001) A Remote Sensing-GIS Evaluation of Urban Expansion and Its Impact on Surface Temperature in the Zhujiang Delta, China. International Journal of Remote Sensing, 22, 1999-2014.

[2] Zampella, R.A., Procopio, N.A., Lathrop, R.G. and Dow, C.L. (2007) Relationship of Land-Use/Land-Cover Patterns and Surface-Water Quality in the Mullica River Basin. Journal of the American Water Resources Association, 43, 594-604. https://doi.org/10.1111/j.1752-1688.2007.00045.x

[3] Tang, V., Titov, V. and Chamberlin, C.D. (2005) Development, Testing, and Applications of Site-Specific Tsunami Inundation Models for Real-Time Forecasting. 
Journal of Geophysical Research, 114, C12025.

[4] Stohlgren, T.J., Bull, K.A. and Otsuki, Y. (1998) Comparison of Rangeland Vegetation Sampling Techniques in the Central Grasslands. Journal of Range Management, 51, 164-172. https://doi.org/10.2307/4003202

[5] Bronstert, A., Niehoff, D. and Burger, G. (2002) Effects of Climate and Land-Use Change on Storm Runoff Generation: Present Knowledge and Modelling Capabilities. Hydrological Processes, 16, 509-529. https://doi.org/10.1002/hyp.326

[6] Griffiths, J.F. (1976) Applied Climatology-An Introduction. Oxford University Press, Oxford.

[7] Adebayo, A.A. and Zemba, A.A. (2003) Analysis of Micro-Climatic Variations in Jimeta-Yola, Nigeria. Global Journal of Social Sciences, 2, 79-88. https://doi.org/10.4314/gjss.v2i1.22769

[8] Karl, T.R., Diaz, H.E. and Kukla, G. (1988) Urbanization, Its Effects and Detection on the United States Climate Record. Journal of Climatology, 1, 1099-1123. https://doi.org/10.1175/1520-0442(1988)001<1099:UIDAEI >2.0.CO;2

[9] Ifatimehin, O.O. (2007) An Assessment of Urban Heat Island of Lokoja Town and Surrounding Using Landsat ETM Data.

[10] Zhengming, W. and Dozier, J. (1989) Land-Surface Temperature Measurement from Space: Physical Principles and Inverse Modeling. IEEE Transactions on Geoscience and Remote Sensing, 27, 268-278.

[11] Dubayah, D.J. and Davis, F.W. (1990) Topographic Distribution of Clear-Sky Radiation over the Konza Prairie.

[12] Wang, W., Liang, S. and Tilden, M. (2008) Validating MODIS Land Surface Temperature Products Using Long-Term Nighttime Ground Measurements. Remote Sensing of Environment, 112, 623-635. https://doi.org/10.1016/j.rse.2007.05.024

[13] Keramitsoglou, I., Kiranoudis, C.T., Ceriola, G., Weng, Q. and Rajasekar, U. (2011) Identification and Analysis of Urban Surface Temperature Patterns in Greater Athens, Greece, Using MODIS Imagery. Remote Sensing of Environment, 115, 3080-3090. https://doi.org/10.1016/j.rse.2011.06.014

[14] Dash, P., Göttsche, F.-M., Olesen, F.-S. and Fischer, H. (2002) Land Surface Temperature and Emissivity Estimation from Passive Sensor Data: Theory and Practice-Current Trends. International Journal of Remote Sensing, 23, 2563-2594. https://doi.org/10.1080/01431160110115041

[15] Landsberg, H.E. (1981) The Urban Climate. Academic Press, New York.

[16] Akpu, B. and Anger, T.R. (2010) The Impact of Spatial Distribution of Solid Waste Dumps on Infrastructures in Samaru, Zaria Using Geographic Information. A Seminar Presentation at the Department of Geography, ABU, Zaria.

[17] Cheng, Y., Canuto, V.M. and Howard, A.M. (2002) An Improved Model for the Turbulent PBL. Journal of the Atmospheric Sciences, 59, 1550-1565. https://doi.org/10.1175/1520-0469(2002)059<1550:AIMFTT>2.0.CO;2

[18] Jiang, J. and Tian, G. (2010) Analysis of the Impact of Land Use/Land Cover Change on Land Surface Temperature with Remote Sensing. Procedia Environmental Sciences, 2, 571-575. https://doi.org/10.1016/j.proenv.2010.10.062

[19] Ahmed, B., Kamruzzaman, M., Zhu, X., Rahman, M.S. and Choi, K. (2013) Simulating Land Cover Changes and Their Impacts on Land Surface Temperature in Dhaka. Bangladesh Remote Sensing, 5, 5969-5998.

https://doi.org/10.3390/rs5115969 